\title{
Clinicopathological Study of Colorectal Carcinomas
}

B. V. Hari Charan, $(\mathrm{MD})^{1}$, Saumya Bandla, (MD) ${ }^{1 *}$, Shanthi Vissa, $\mathrm{MD}^{2}$, Viswanath Sai. P, $\mathrm{MD}^{1}$, Nandam Mohan Rao, $\mathrm{MD}^{2}$, Byna Shyam Sundara Rao, $\mathrm{MD}^{2}$, Bhavana Grandhi, $\mathrm{MD}^{2}$

${ }^{1}$ Post Graduate, Department of Pathology, Narayana Medical College and Hospital, Nellore, Andhra Pradesh, India

${ }^{2}$ Professor, Department of Pathology, Narayana Medical College and Hospital, Nellore, Andhra Pradesh, India

\begin{tabular}{ll}
\hline DOI: $10.36348 /$ sjpm.2020.v05i01.005 & | Received: 03.01.2020 | Accepted: 19.01 .2020 | Published: 30.01 .2020
\end{tabular}

\section{Abstract}

Background: The aim of this study is reviewing the histopathological spectrum of malignant neoplastic lesions of the large intestine. Methods: This is a retrospective \& prospective study carried out in the department of pathology from June 2017 to June 2019. The specimens from the medical and surgical gastroenterology department were studied. Variables like age, sex, tumor size, location, type of lesion, the histological pattern of patients were studied. Results: In the series of 140 patients of colorectal neoplasm, the maximum number of patients presented in the fourth decade of life $(34.28 \%)$ with a mean age of presentation at 53.7years. The youngest patient with adenocarcinoma was 24years (male) of age, and the oldest one was 80 years (male) of age. The male to female ratio was 1.12:1. The proportion of welldifferentiated carcinoma was highest in left side colon and rectum, whereas the incidence of moderately and poorly differentiated adenocarcinoma was higher on the right-side colon. Conclusion: Adenocarcinoma is the most common histological variant of colon carcinomas showing slight male preponderance and the most common site being rectum.

Keywords: Neoplastic lesions, Adenocarcinoma, Large intestine.

Copyright @ 2020: This is an open-access article distributed under the terms of the Creative Commons Attribution license which permits unrestricted use, distribution, and reproduction in any medium for non-commercial use (NonCommercial, or CC-BY-NC) provided the original author and sources are credited.

\section{INTRODUCTION}

Globally around 800000 new colorectal cancer cases are believed to occur, which accounts for approximately $10 \%$ of all incident cancers, and mortality due to colorectal cancer was nearly 450000 [1]. Although incidence varies widely, with higher incidence rates in North America, Australia, and Europe and lowers in developing countries.

The risk of acquiring colorectal cancer increases with age, and more than $90 \%$ of new cases diagnosed are in patients above 50 years. Generally, colorectal cancer incidence and mortality rates are highest in developed Western nations [1-5]. This may be related to the consumption of high-fat or high red meat diet, and lack of physical activity resulting in obesity and variations in mortality causes over a longitudinal period.

\section{METHODS}

The study was done at the Department of Pathology, Narayana Medical College and Hospital, Nellore, Andhra Pradesh, India. It was done for a period of two years from June 2017 to June 2019. This study was done after taking the ethical approval from the ethical review committee of Narayana medical college, Nellore. The specimens were fixed in $10 \%$ formalin, followed by processing and embedding. Paraffinembedded blocks were cut into 4-5 microns thin sections and stained with Haematoxylin and eosin.

\section{RESULTS}

In the present series of 140 patients of colorectal carcinomas maximum number of patients presented in the fourth decade of life (34.28\%), minimum cases were $(5.71 \%)$ between 20 - 30 years (Table-1). The male to female sex ratio in the present study was 1.12:1 (Table-2).

The youngest patient with adenocarcinoma was 24 years (male) of age, and the oldest one was 80 years (male) of age (Table-3). The mean age of presentation of colorectal cancers in this study was 53.7 years of age.

It was observed that carcinoma of left-sided colon cancer constituting $112(80.00 \%)$ cases was more common than carcinoma of right-sided colon cancers comprises of $28(20.00 \%)$, with a left-sided carcinoma to right-sided carcinoma ratio was 4:1 (Table-4). 
Rectum was the most affected site constituting about $62(44.28 \%)$ cases, followed by ascending colon with $18(12.85 \% \%)$ cases, sigmoid colon with $18(12.85 \% \%)$ cases, descending colon with 16 $(11.42 \%)$ cases, caecum with $4(2.85 \%)$ cases and splenic flexure and anal canal constituting 06 (4.28\%) and $16(11.42 \%)$ cases respectively (Table-5).
The predominant histological type in the present study was adenocarcinoma, of which welldifferentiated type in $78(55.71 \%)$, moderately differentiated type in $32(22.85 \%)$ (Figure-1) and poorly differentiated type in $12(8.57 \%$ ) (Figure-2) cases while others constituted (12.84\%) which includes mucinous adenocarcinoma also (Figure-3).

Table 1: Age Profile of Patients with Colorectal Carcinoma

\begin{tabular}{|l|l|l|}
\hline AGE & NO OF CASES & PERCENTAGE \\
\hline 20-30years & 08 & $5.71 \%$ \\
\hline 31-40years & 14 & $10.00 \%$ \\
\hline 41-50years & 48 & $34.28 \%$ \\
\hline 51-60years & 22 & $15.71 \%$ \\
\hline 61-70years & 26 & $18.57 \%$ \\
\hline 71-80years & 22 & $15.71 \%$ \\
\hline
\end{tabular}

Table-2: Sex Wise Distribution of Cases

\begin{tabular}{|l|l|l|}
\hline SEX & CASES $(\mathbf{n}=140)$ & PERCENTAGE (\%) \\
\hline MALES & 74 & 52.86 \\
\hline FEMALES & 66 & 47.14 \\
\hline
\end{tabular}

Table-3: Age-Sex Wise Distribution of Cases

\begin{tabular}{|l|l|l|}
\hline AGE & MALE $(\mathbf{n = 7 4 )}$ & FEMALE(n=66) \\
\hline 20-30years & $06(4.28 \%)$ & $02(1.43 \%)$ \\
\hline 31-40years & $06(4.28 \%)$ & $08(5.71 \%)$ \\
\hline 41-50years & $20(14.28 \%)$ & $28((20.00 \%)$ \\
\hline 51-60years & $10(7.14 \%)$ & $12(8.57 \%)$ \\
\hline 61-70years & $18(12.85 \%)$ & $08(5.71 \%)$ \\
\hline 71-80years & $14(10.00 \%)$ & $08(5.71 \%)$ \\
\hline
\end{tabular}

Table-4: Distribution of Malignant Lesions in Large Intestine Based on Site (Right Vs Left)

\begin{tabular}{|l|l|l|l|}
\hline RIGHT COLON & NO OF CASES & LEFT COLON & NO OF CASES \\
\hline CEACUM & $04(2.85 \%)$ & DESCENDING COLON & $16(11.42 \%)$ \\
\hline ASCENDING COLON & $18(12.85 \%)$ & SIGMOID COLON & $18(12.85 \%)$ \\
\hline SPLEENIC FLEXURE & $06(4.28 \%)$ & RECTUM & $62(44.28 \%)$ \\
\hline & & ANAL CANAL & $16(11.42 \%)$ \\
\hline TOTAL & $28(19.98 \%)$ & & $112(79.97 \%)$ \\
\hline
\end{tabular}

Table-5: Site of the Primary Tumor

\begin{tabular}{|l|l|l|}
\hline LOCATION & NO OF CASES & PERCENTAGE \\
\hline Rectum & 62 & $44.28 \%$ \\
\hline Sigmoid colon & 18 & $12.85 \%$ \\
\hline Splenic flexure & 06 & $4.28 \%$ \\
\hline Ascending colon & 18 & $12.85 \%$ \\
\hline Descending colon & 16 & $11.42 \%$ \\
\hline Caecum/ileocaecum & 04 & $02.85 \%$ \\
\hline Anal canal & 16 & $11.42 \%$ \\
\hline
\end{tabular}




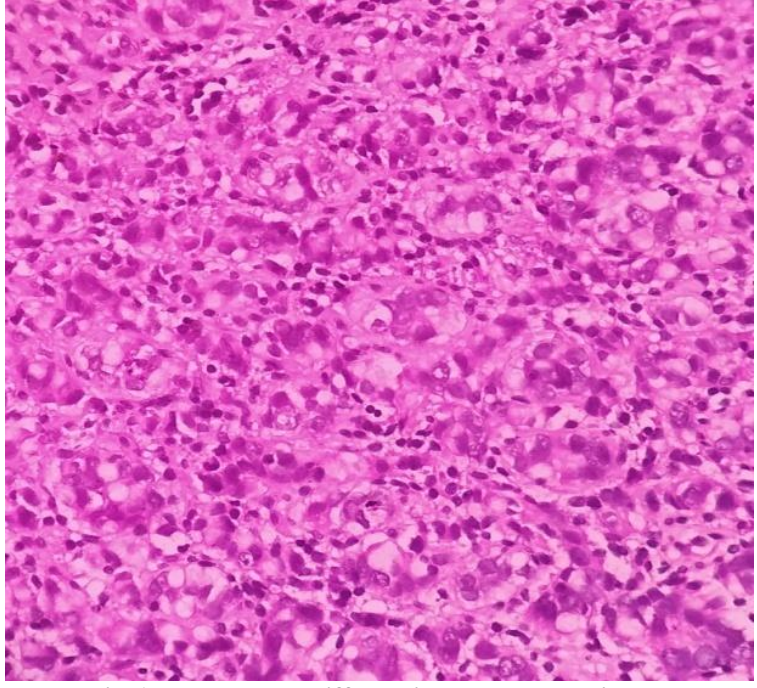

Fig-1: Moderately differentiated adenocarcinoma

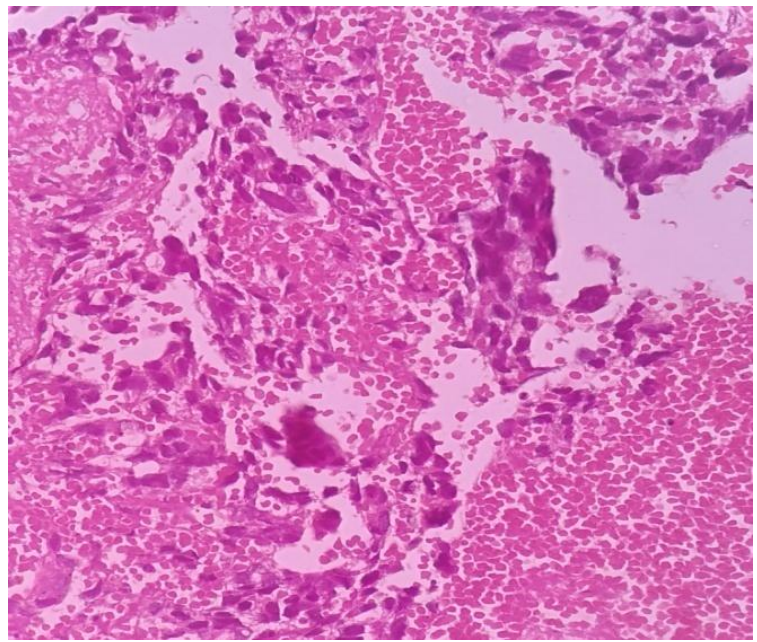

Fig-2: Poorly differentiated adenocarcinoma

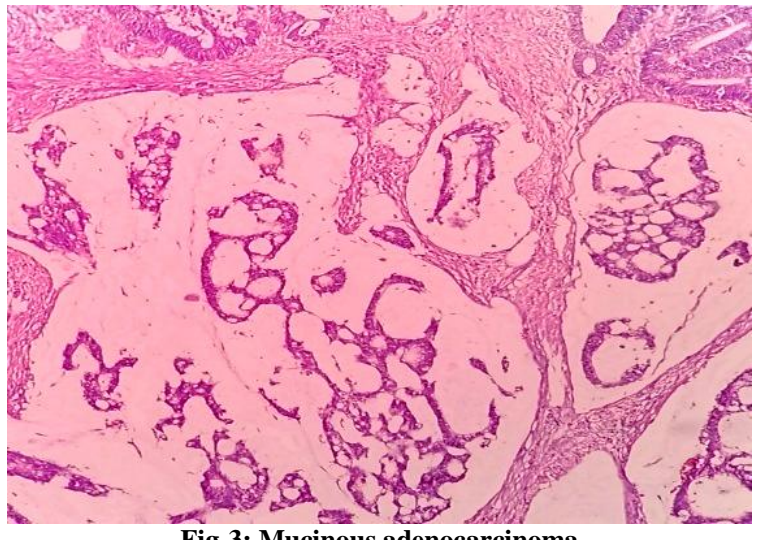

Fig-3: Mucinous adenocarcinoma

\section{DISCUSSION}

Colorectal cancer is a disease with a significant worldwide burden in terms of patient sufferings and the cost of treatment. Colorectal cancer is the most common malignant neoplasm in the gastrointestinal tract, and worldwide colorectal cancer is the second most common among women and the 3rd most common among men [6]. Incidence increases after 35 years of age and rapidly rises after 50 years of age and peak in the seventh decade. The majority, nearly $90 \%$ of cancers, occur after 50 years of age. Although cases have been reported in young children and adolescents. In the present study, the most common age group of colorectal cancer was 50 to 65 (24.2\%) followed by 61 to $75(20 \%)$ which was consistent with studies of Al-Samawi et al., [7]. In our study males outnumbered females with male to female ratio of 1.12:1 [8-10].

Around $61.43 \%$ of patients had bleeding per rectum as their common presenting symptom. Other presenting symptoms were altered bowel habits, pain abdomen, and anemia. A minority of the patients presented with rare clinical features of subacute intestinal obstruction or distention $[11,12]$.

Epidemiologic studies have linked an increased risk of colorectal cancer with a diet rich in red meat and animal fat, with a low-fiber diet and low overall intake of fruits and vegetables. The majority of patients in the present study were non-vegetarians consuming red meat, with obesity and lack of physical activity. This is inconsistent with studies of Larson et al., [13] Sandhu et al., [14] and Cross et al., [15].

The carcinoma of left-sided colon exceeds the number of cases of carcinoma right-sided colon, which is consistent with the world's literature and other Indian studies $[16,10]$.

A study by Kumar et al., [17] revealed that rectum was more commonly involved in $29.6 \%$ cases, sigmoid colon in $26.5 \%$, ascending Colon in $21 \%$, descending Colon in $17.9 \%$, and transverse Colon in $4.9 \%$. Similar results were observed in the present study, rectum with most commonly involved (44.28\%), followed by sigmoid colon and ascending colon constituting the maximum number of colon cancers $(25.7 \%)$.

The increasing prevalence of obesity with decreasing physical activity in many parts of the world, resulting from "Westernization," is likely to raise the incidence of colorectal carcinoma in countries with low rates if these behaviors are not modified.

\section{CONCLUSION}

- Adenocarcinoma colon is the most common histological tumor type in the large intestine, which is similar to that seen in India and the rest of the World.

- The most common site for a malignant lesion in our population is of ascending colon.

- Colorectal carcinoma shows an increasing trend towards a younger age group $(\leq 30$ years), constituting $5.71 \%$ of total cases, with more number of cases among females with unfavorable histological grade. 
- Colon carcinoma is seen increasing in frequency in the younger population, so a person having bowel symptoms with iron deficiency anemia should undergo proper evaluation as early as possible.

Funding: No funding sources.

Conflict of Interest: None declared.

Ethical Approval: Approved by the institutional ethical committee.

\section{REFERENCES}

1. Parkin, D. M., Pisani, P., \& Ferlay, J. (1999). Global cancer statistics. CA: a cancer journal for clinicians, 49(1), 33-64.

2. Jemal, A., Siegel, R., Ward, E., Murray, T., Xu, J., \& Thun, M. J. (2007). Cancer statistics, 2007. CA: a cancer journal for clinicians, 57(1), 43-66.

3. Landis, S. H., Murray, T., Bolden, S., \& Wingo, P. A. (1998). Cancer statistics, 1998. CA: a cancer journal for clinicians, 48(1), 6-29..

4. Armstrong, B., \& Doll, R. (1975). Environmental factors and cancer incidence and mortality in different countries, with special reference to dietary practices. International journal of cancer, 15(4), 617-631.

5. Henderson, M. M. (1992). International differences in diet and cancer incidence. $J$ Natl Cancer Inst Monogr, 12, 59-63.

6. Ferlay, J., Shin, H. R., Bray, F., Forman, D., Mathers, C., \& Parkin, D. M. (2010). Estimates of worldwide burden of cancer in 2008: GLOBOCAN 2008. International journal of cancer, 127(12), 2893-2917.

7. Al-Samawi, A. S., \& Phill, M. (2013). Histopathological Profile of Colorectal Cancer in Yemen-An Eight Years Retrospective Study. Yemeni Journal for Medical Sciences, 7.

8. Caldarola, V. T., Jackman, R. J., Moertel, C. G., \& Dockerty, M. B. (1964). Carcinoid tumors of the rectum. The American Journal of Surgery, 107(6), 844-849.

9. Yoon, S. N., Yu, C. S., Shin, U. S., Kim, C. W., Lim, S. B., \& Kim, J. C. (2010). Clinicopathological characteristics of rectal carcinoids. International journal of colorectal disease, 25(9), 1087-1092.

10. Javid, G., Zargar, S. A., Rather, S., Khan, A. R., Khan, B. A., Yattoo, G. N., ... \& Bashir, A. S. D. (2011). Incidence of colorectal cancer in Kashmir valley, India. Indian Journal of Gastroenterology, 30(1), 7-11.

11. Stein, W., Farina, A., Gaffney, K., Lundeen, C., Wagner, K., \& Wachtel, T. (1993). Characteristics of colon cancer at time of presentation. Family practice research journal, 13(4), 355-363.

12. Hamilton, W., Lancashire, R., Sharp, D., Peters, T. J., Cheng, K. K., \& Marshall, T. (2009). The risk of colorectal cancer with symptoms at different ages and between the sexes: a case-control study. BMC medicine, 7(1), 17.

13. Larsson, S. C., Rafter, J., Holmberg, L., Bergkvist, L., \& Wolk, A. (2005). Red meat consumption and risk of cancers of the proximal colon, distal colon and rectum: the Swedish Mammography Cohort. International journal of cancer, 113(5), 829-834.

14. Sandhu, M. S., White, I. R., \& McPherson, K. (2001). Systematic review of the prospective cohort studies on meat consumption and colorectal cancer risk: a meta-analytical approach. Cancer Epidemiology and Prevention Biomarkers, 10(5), 439-446.

15. Cross, A. J., Ferrucci, L. M., Risch, A., Graubard, B. I., Ward, M. H., Park, Y., ... \& Sinha, R. (2010). A large prospective study of meat consumption and colorectal cancer risk: an investigation of potential mechanisms underlying this association. Cancer research, 70(6), 24062414.

16. Xu, A. G., Yu, Z. J., Jiang, B., Wang, X. Y., Zhong, X. H., Liu, J. H., ... \& Gan, A. H. (2010). Colorectal cancer in Guangdong Province of China: a demographic and anatomic survey. World journal of gastroenterology: WJG, 16(8), 960.

17. Kumar, S., Burney, I. A., Zahid, K. F., Souza, P. C. D., Belushi, M. A., Meki TDMWA, F. M., \& Mansour, S. (2015). Colorectal cancer patient characteristics, treatment and survival in Oman-a single center study. Asian Pac $J$ Cancer Prev, 16(12), 4853-4858. 